\title{
ErbB3 Phosphorylation as Central Event in Adaptive Resistance to Targeted Therapy in Metastatic Melanoma: Early Detection in CTCs during Therapy and Insights into Regulation by Autocrine Neuregulin
}

\author{
Ciro Francesco Ruggiero ${ }^{1,2,+}$, Debora Malpicci ${ }^{2,+}$, Luigi Fattore ${ }^{3}$, Gabriele Madonna ${ }^{4}$, \\ Vito Vanella ${ }^{4}$, Domenico Mallardo ${ }^{4}\left(\mathbb{D}\right.$, Domenico Liguoro ${ }^{5}$, Valentina Salvati ${ }^{1}$, \\ Mariaelena Capone ${ }^{4}$, Barbara Bedogni ${ }^{6,7}$, Paolo Antonio Ascierto ${ }^{4}$, Rita Mancini ${ }^{5, \ddagger}$ and \\ Gennaro Ciliberto ${ }^{8, *, \ddagger}$ \\ 1 Preclinical Models and New Therapeutic Agents Unit, IRCCS Regina Elena National Cancer Institute, \\ 00144 Rome, Italy; cirofrancescoruggier@libero.it (C.F.R.); salvati.sv@gmail.com (V.S.) \\ 2 Department of Experimental and Clinical Medicine, University “Magna Graecia” of Catanzaro, \\ 88100 Catanzaro, Italy; malpicci.debora@gmail.com \\ 3 Department of Molecular and Clinical Medicine, Laboratory Affiliated to Istituto Pasteur Italia Fondazione \\ Cenci Bolognetti, University of Rome "Sapienza", 00161 Rome, Italy; luigifattore1985@gmail.com \\ 4 Department of Melanoma, Oncologic Immunotherapy and Innovative Therapies Istituto Nazionale Tumori \\ IRCCS, “Fondazione G. Pascale”, 80131 Naples, Italy; g.madonna@istitutotumori.na.it (G.M.); \\ v.vanella@istitutotumori.na.it (V.V.); d.mallardo@istitutotumori.na.it (D.M.); \\ me.capone@istitutotumori.na.it (M.C.); p.ascierto@istitutotumori.na.it (P.A.A.) \\ 5 Department of Molecular and Clinical Medicine, University of Rome "Sapienza", 00161 Rome, Italy; \\ domenico.liguoro@uniroma1.it (D.L.); rita.mancini@uniroma1.it (R.M.) \\ 6 Department of Biochemistry, Case Western Reserve University, Cleveland, OH 44106, USA; \\ bxb602@miami.edu \\ 7 Department of Dermatology, Miller School of Medicine, Miami, FL 33136, USA \\ 8 Scientific Directorate, IRCCS Regina Elena National Cancer Institute, 00144 Rome, Italy \\ * Correspondence: gennaro.ciliberto@ifo.gov.it \\ + These two authors contributed equally. \\ $\ddagger$ These two authors contributed equally.
}

Received: 8 August 2019; Accepted: 20 September 2019; Published: 25 September 2019

\begin{abstract}
In recent years the introduction of target therapies with BRAF and MEK inhibitors (MAPKi) and of immunotherapy with anti-CTLA-4 and anti-PD-1 monoclonal antibodies have dramatically improved survival of metastatic melanoma patients. Despite these changes drug resistance remains a major hurdle. Several mechanisms are at the basis of drug resistance. Particular attention has been devoted over the last years to unravel mechanisms at the basis of adaptive/non genetic resistance occurring in BRAF mutated melanomas upon treatment with to MAPKi. In this paper we focus on the involvement of activation of ErbB3 receptor following early exposure of melanoma cells to BRAF or MEK inhibitors, and the following induction of PI3K/AKT pathway. Although different mechanisms have been invoked in the past at the basis of this activation we show here with a combination of approaches that autocrine production of neuregulin by melanoma cells is a major factor responsible for ErbB3 phosphorylation and downstream AKT activation. Interestingly the kinetic of neuregulin production and of the ensuing ErbB3 phosphorylation is different in different melanoma cell lines which underscores the high degree of tumor heterogeneity. Moreover, heterogeneity is further highlighted by the evidence that in different cell lines neuregulin upregulation can occur at the transcriptional or at the post-transcritpional level. Finally we complement our study by showing with a liquid biopsy assay that circulating tumor cells (CTCs) from melanoma patients undergo upregulation of ErbB3 phosphorylation in vivo shortly after initiation of therapy.
\end{abstract}


Keywords: melanoma; target therapy; adaptive resistance; ErbB3 phosphorylation; CTCs; neuregulin1

\section{Introduction}

Malignant melanoma is the most aggressive tumour of the skin, which arises from the transformation of melanocytes. Its incidence has increased significantly in the last decades [1]. Over the past few years thanks to the development of immunotherapy with immune checkpoint inhibitors and targeted therapy against kinases of the RAS/BRAF/MAPK pathway, the clinical outcome has improved dramatically with the achievement of long term benefit in approximately $50 \%$ of patients with metastatic disease [2,3].

Approximately $50 \%$ of melanomas at diagnosis harbour mutations in the B-Raf proto-oncogene serine/threonine kinase (BRAF) gene, a key serine-threonine kinase in the MAPK signalling pathway. The most common mutation is a substitution of a valine to glutamic acid (V600E) which occurs in about $90 \%$ of cases, but also other mutations V600K-D-R may occur [4]. All these aminoacid substitutions result in constitutive kinase activation and uncontrolled cell growth. This led initially to the clinical development of BRAF inhibitors such as vemurafenib or dabrafenib with promising results in terms of high objective response rates, and improved survival [5]. However, the strong evidence that disease relapse due to drug resistance occurs shortly after initiation of BRAF inhibitor monotherapy, and that this is linked to the emergence of bypass mutations in resistant tumours which cause reactivation of the RAS/BRAF/MEK pathway [2], led to the development of dual therapies with BRAF and MEK inhibitors. Combo therapy with a BRAF and a MEK inhibitor has, therefore, become the current standard of care [6]. Unfortunately, however, also dual therapy, although being able to provide more durable disease control and improved survival vs. monotherapy, is plagued by the development of drug resistance $[2,6]$.

Intense efforts have been directed to identify additional mechanisms of resistance, in particular adaptive non-genetic mechanism, which may help melanoma cells to survive the stress linked to the exposure to BRAF/MEK inhibitors. In this context, members of the EGF receptor family have emerged as promising targets in the treatment of various forms of cancer, due to their fundamental involvement in the activation of the proliferation and survival pathway induced by the PI3K / AKT pathway [7]. In particular the ErbB3 receptor has been identified as one of the key elements of malignancy, being, in fact, one of the most potent activator of the AKT pathway because of the presence of six tyrosine residues in its intracellular domain which when phosphorylated represent docking sites for proteins involved in proliferative and pro-survival signalling [8-12]. ErbB3 is frequently over-expressed in human melanoma cells [8,9]. Immuno-histochemical analysis showed high ErbB3 levels of expression in melanoma metastases and its association with disease progression $[13,14]$. ErbB3 is also involved in the development of resistance by tumour cells to conventional anti-EGFR and anti-ErbB2 therapies [15-17]. Furthermore, ErbB3 signalling induced by its natural ligand, neuregulin (NRG), is able to inhibit the differentiation of melanocytes, promoting the proliferation of melanoma cells [18]. Previous studies have shown that ErbB3 is a key factor in the development of adaptive resistance to BRAF and Mek inhibitors, albeit with different mechanisms, and that ErbB3 inhibition with monoclonal antibodies is able to potentiate the efficacy of target therapy in melanoma $[8,15,19-21]$. In this study we have provided further insights into the central role of ErbB3 and its mechanism of activation.

\section{Results}

2.1. BRAF-Mutated Melanoma Cell Lines Show Different Activation Kinetics of the pErbB3/pAKT Axis After Exposure to BRAF Inhibitors

In order to confirm if the main mechanism responsible for ErbB3 phosphorylation observed in melanoma cells exposed to BRAF inhibitors is the activation of an autocrine loop, we assessed the effect 
of the conditioned medium (CM) obtained from different cell lines after incubation with vemurafenib as a BRAF inhibitor. In detail three BRAF-mutated melanoma cell lines (WM266, WM115 and LOX IMVI) were treated with vemurafenib $(0.5 \mu \mathrm{M})$ for different times $(2 \mathrm{~h}, 8 \mathrm{~h}$ and $24 \mathrm{~h})$. Of note we decided to use a dose of $0.5 \mu \mathrm{M}$ BRAFi for western blotting experiments because different cell lines have different degrees of sensitivity to BRAFi and this drug concentration is able to inhibit cell growth efficiently in all cell lines used $[15,19]$. The conditioned medium was collected and added to starved melanoma cells for $30 \mathrm{~min}$ (Figure 1A). In parallel melanoma cell cultures from the same cell lines were directly exposed to vemurafenib. Cell extracts were then subjected to Western Blot analysis (Figure 1B and Figure S1). The results show a strong phosphorylation of ErbB3 in melanoma cells upon treatment with CM from BRAF inhibitor-exposed melanoma cells, similar to what happens after direct cell exposure to the same BRAF inhibitor. Of note, increase of pErbB3, which is always accompanied by an increase of pAKT levels, occurs with different kinetics in the three cells lines: in WM266 is already high at $2 \mathrm{~h}$, remains constant at $8 \mathrm{~h}$ and declines thereafter; in WM115 is low at $2 \mathrm{~h}$, maximal at $8 \mathrm{~h}$ and sharply declines after $24 \mathrm{~h}$; in LOX IMVI is high only after $24 \mathrm{~h}$. These findings support the notion that melanoma cells respond to BRAF inhibitors exposure by releasing in the culture media one or more soluble factor able to activate the ErbB3/AKT axis.

$\underline{A}$
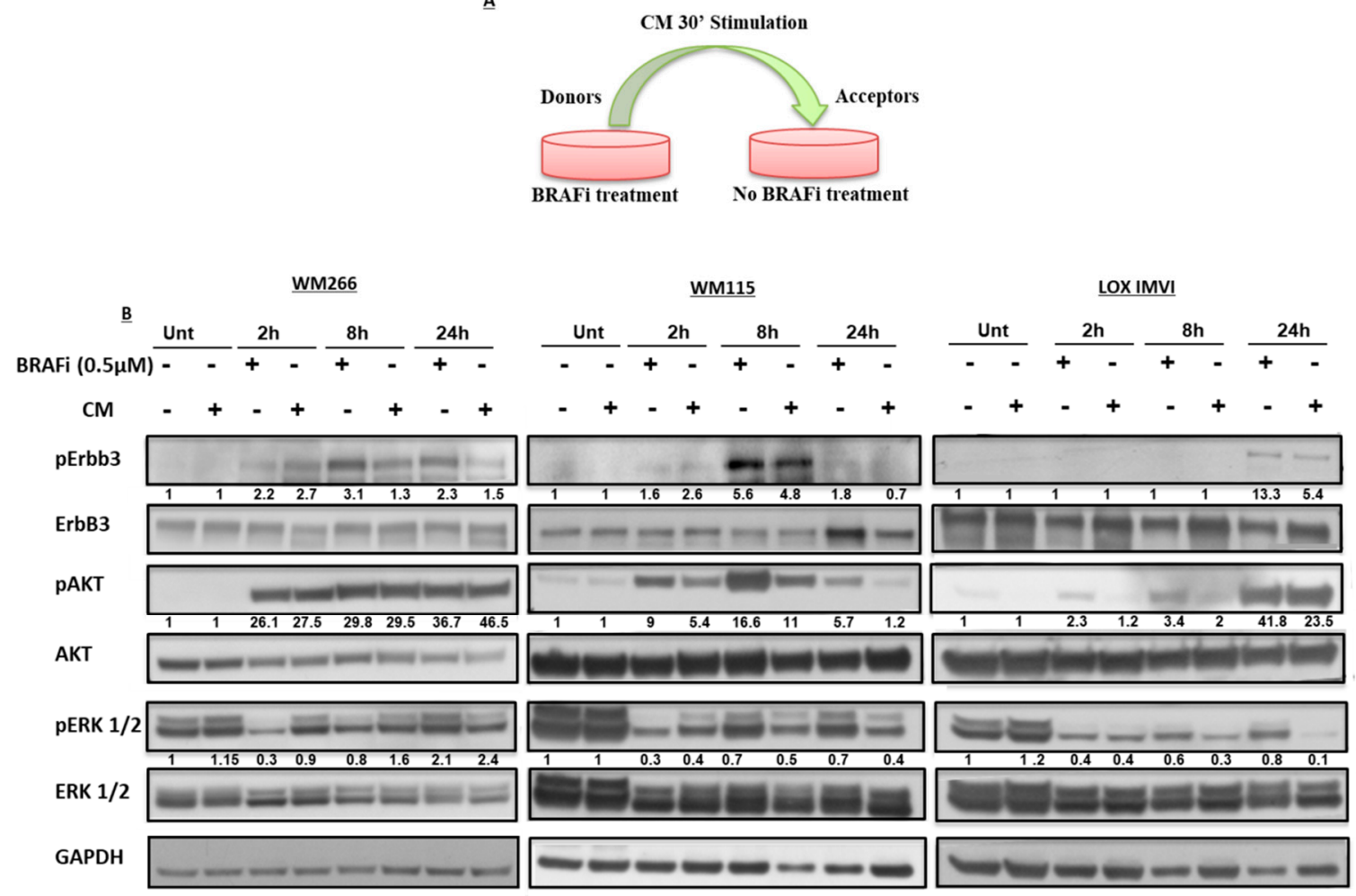

Figure 1. The activation of pErbB3/pAKT survival pathway occurs in different times upon BRAFi exposure in BRAF-mutated melanoma cell lines. (A) In the schematic representation of the experiment unstimulated melanoma cells were exposed for $30 \mathrm{~min}$ with conditioned medium (CM) coming from BRAF inhibitor-stimulated melanoma cells. (B) WM266 (left panel), WM115 (middle panel) and LOX IMVI (right panel) melanoma cell lines were starved and treated with BRAFi $(0.5 \mu \mathrm{M})$ for $2 \mathrm{~h}, 8 \mathrm{~h}$ and 24 h. pErbB3/ErbB3, pERK/ERK and pAkt/Akt values are expressed as fold change with respect to the control unstimulated cells expression levels by densitometric analysis. Conditioned medium from BRAF inhibitor-stimulated melanoma cells induce an early pErbB3/pAKT axis activation as shown in western blotting experiments. 
2.2. Early Release of NRG-1 Is Responsible for the Activation of the ErbB3 Receptor and NRG-1 Inhibition Potentiates the Growth Inhibitory Effect of BRAF Inhibition

In order to assess the involvement of the ErbB3 ligand neuregulin-1 (NRG-1) we evaluated the levels of secreted NRG-1 in WM266 cell medium by immunoassay experiments (see Materials and Methods section) (Figure 2A and Figure S2).

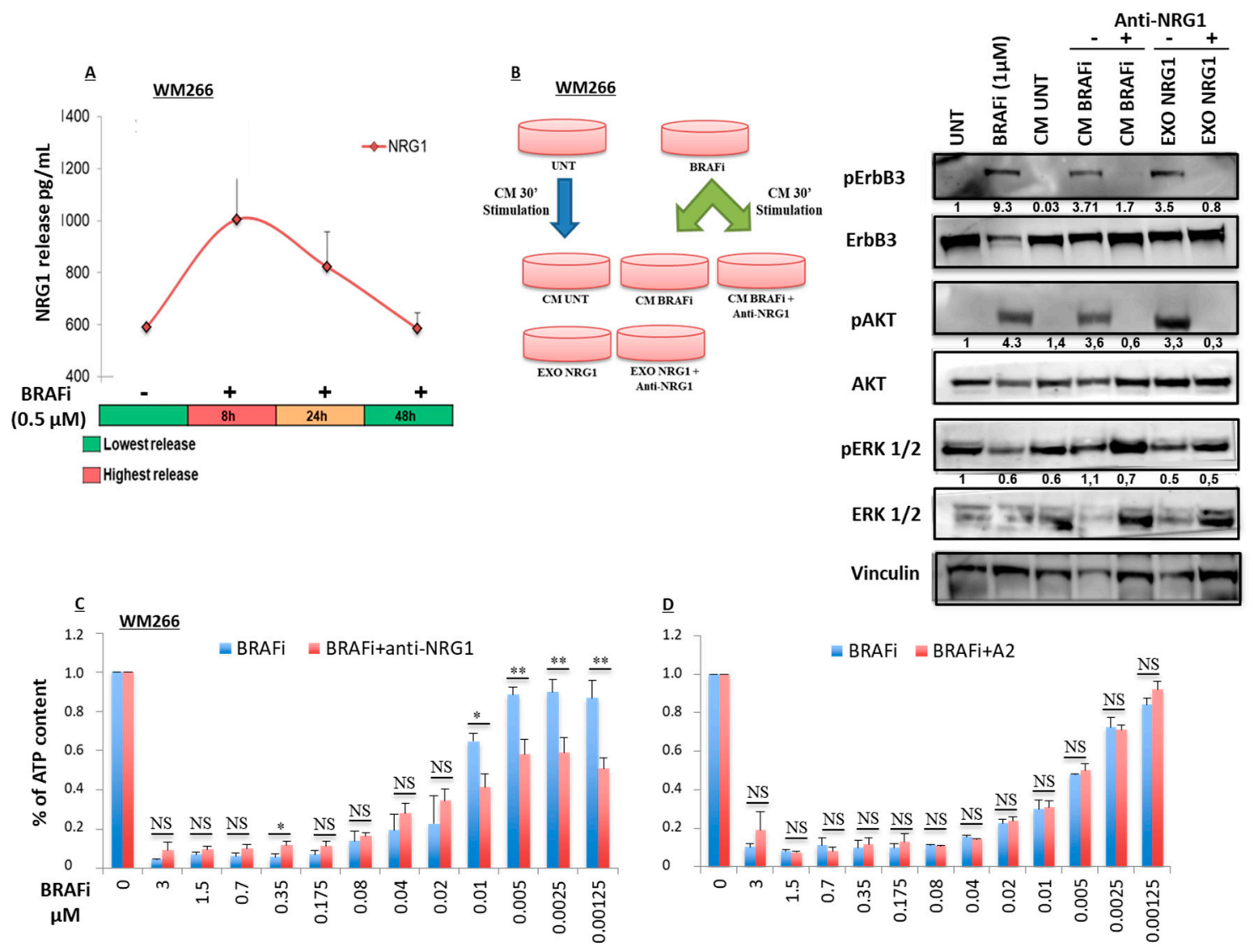

Figure 2. The inhibition of released NRG-1 enhanced the inhibitory effect of BRAFi on WM266 cell growth. (A) WM266 melanoma cell lines were starved and then treated with BRAFi $(0.5 \mu \mathrm{M})$ for different times ( $8 \mathrm{~h}, 24 \mathrm{~h}$ and $48 \mathrm{~h}$ ). Cell media was collected and analyzed by immunoassay using the NRG-1 capture antibody. Results shows that increasing levels of NRG-1 are released in cell media upon short term BRAF inhibitor treatment in WM266 melanoma cells. (B) In the schematic representation of the experiment WM266 cell line was serum starved for $24 \mathrm{~h}$ and later treated or not with BRAFi $(1 \mu \mathrm{M})$ for other $24 \mathrm{~h}$ before collecting its culture medium or also called conditioned media $(\mathrm{CM})$. Then the CM were subsequently pre-incubated or not with the anti-NRG1 antibody for 1h. WM266 cells treated for $1 \mathrm{~h}$ with the untreated conditioned medium (untreated CM) or BRAFi-stimulated (BRAFi $\mathrm{CM}$ ) were pre-incubated or not with exogenus neuregulin-1 (EXO NRG1). The treatment with the anti-HRG antibody completely abrogates both ErbB3 and AKT phosphorylation induced by BRAFi CM and EXO NRG1 through western blotting assay. The expression of pErbB3/ ErbB3, pERK/ERK and pAKT/ATK was evaluated by densitometric analysis and expressed as fold change with respect to the control unstimulated cells to which value $=1$ was assigned. (C) Anti-NRG1 blocking peptide improved the inhibitory effect of BRAFi on WM266 cell growth especially at lower drug doses as evidenced by a lower ATP release. (D) Conversely the use of a non-efficient anti ErbB3 antibody (A2) used as control [15], did not enhances the inhibitory effect of BRAFi on cell growth. $p$ value was calculated using the T-test whose significance is expressed as $p<0.05$. $^{*}: p<0.05,{ }^{* *}: p<0.01$, NS: $p>0.05$.

The results show that exposure to BRAF inhibitor is able to induce a strong and fast increase of secreted NRG-1 in WM266-derived cell medium. In particular, a high amount of neuregulin-1 (more 
than 10-fold) was detected shortly after drug exposure which gradually declined at later time points. Furthermore, to confirm that phosphorylation of ErbB3 receptor is a consequence of increased NRG-1 production by melanoma cells we decided first to treat WM266 melanoma cells with vemurafenib $(0.5 \mu \mathrm{M})$ or not for $24 \mathrm{~h}$. Then CM was collected and pre-incubated with a neutralizing antibody against NRG-1 (Anti-NRG1) for 1h before incubation with starved WM266 cells. Western blotting results clearly show that Anti-NRG1 completely abrogated the phosphorylation of ErbB3 receptor and the activation of the PI-3K/pAKT pathway (Figure 2B and Figure S3). Moreover, viability assays showed that the Anti-NRG1 enhanced the inhibitory effect of BRAFi on WM266 cell growth especially at lower drug doses (Figure 2C,D). These data have been confirmed in colony formation assays both in WM266 and WM115 cells as reported in Figure S4. As a control a non-neutralizing Anti-ErbB3 antibody (A2) [15] was unable to exert an inhibitory effect on cell proliferation (Figure 2D).

\subsection{BRAF-Mutated Melanoma Cells Show Different Patterns of Changes in ErbB3, NRG-1 and FOXD3 Gene Expression Levels after BRAFi Treatment}

To better investigate the different kinetics of ErbB3 activation in the three different cells lines, WM266, WM115 and LOX IMVI were exposed to vemurafenib from 2 to $72 \mathrm{~h}$, cell extracts were prepared and subjected to western blotting. Results demonstrated that phospho-ErbB3 follows similar pattern in all three lines, with an average peak of activation at $12 / 24 \mathrm{~h}$. It is important to point out that only in WM266 cells there is a slight and earlier activation of the receptor before $12 \mathrm{~h}$. As to the total ErbB3 protein, it is stable until $48 \mathrm{~h}$ in WM266 and WM115 cells following BRAF inhibition. Differently, in LOX IMVI cells ErbB3 protein increases with a peak at $12 \mathrm{~h}$ and then decreases in its expression levels from 24 to $72 \mathrm{~h}$ (Figure 3A and Figure S5).

In order to further assess changes in the expression levels of NRG-1, ErbB3 and Forkhead box D3 (FOXD3) genes, quantitative RT-PCR analysis was carried out on total RNA extracted from cells exposed to vemurafenib at different times (Figure S6). FOXD3 was chosen since it is a known regulator of ErbB3 gene expression [22]. The results are diagrammatically summarized in Figure 2B using a color coded scheme (Figure 3B). In synthesis we observed the existence of three different patterns of changes in ErbB3, NRG-1 and FOXD3 gene expression levels over time: (1) in WM266, NRG-1 and FOXD3 mRNA levels increase early after drug exposure $(2 \mathrm{~h})$ followed by an increase of ErbB3 mRNA at a later times (48-72 h); (2) in WM115 a strong increase of NRG-1 and FOXD3 mRNA levels occurs at intermediate times (12-24 h), which still precedes the increase of ErbB3 expression (48-72h); (3) finally in LOX IMVI, M14 and A375 we observed a late and simultaneous increase (48-72 h) of the expression levels of all three genes.

While these data underscore the strong degree of heterogeneity of melanoma cell lines, they confirm that one of the prominent and constant adaptive response is the upregulation of NRG-1 expression. Interestingly in none of the three cells lines NRG-1 upregulation follows temporally FOXD3 upregulation. Although we have not carried out gene silencing studies of FOXD3, based on the kinetics of expression, we tend to exclude therefore that FOXD3 is involved in induction of NRG-1 expression. 


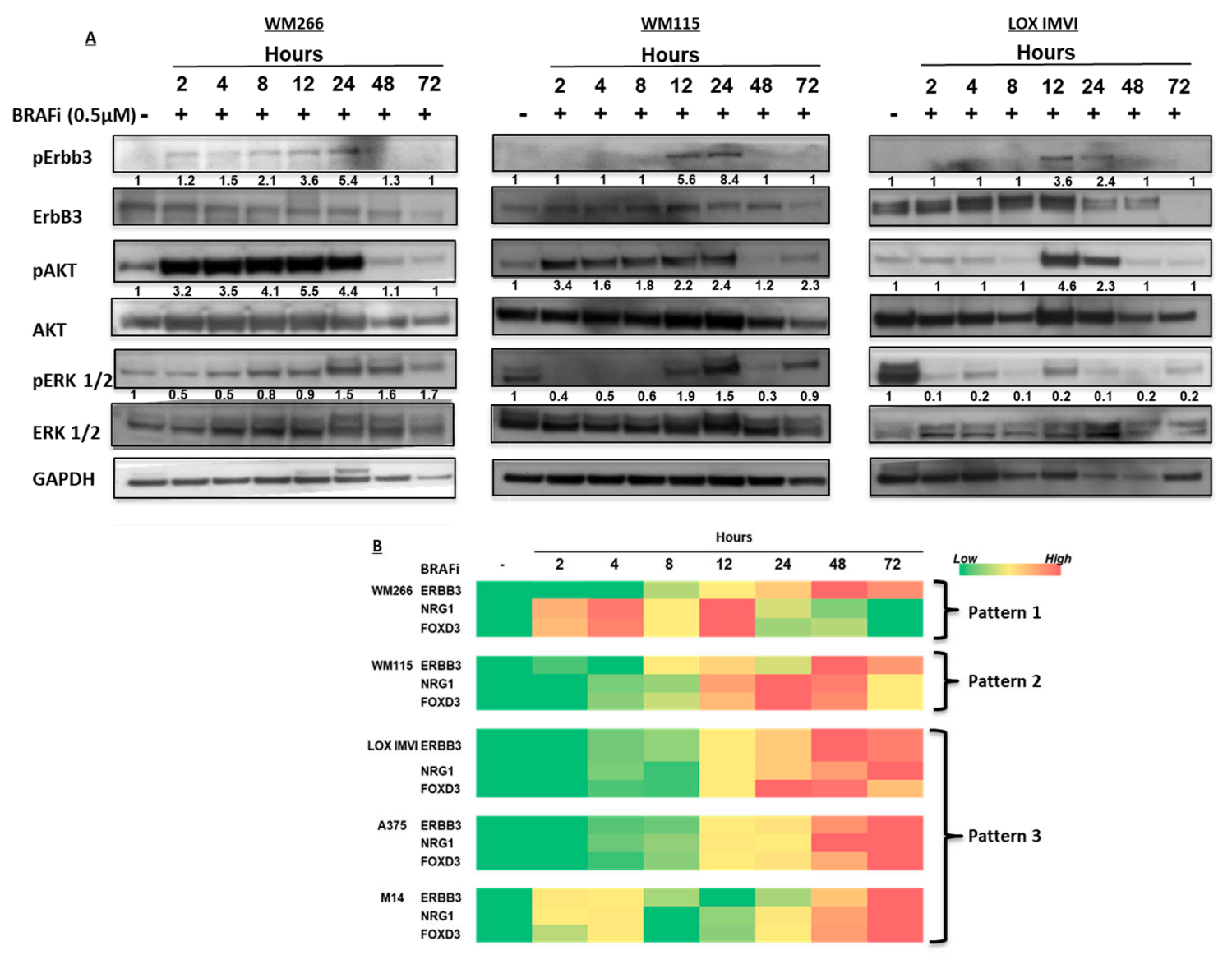

Figure 3. Different kinetics of ErbB3 activation occur in BRAF-mutated melanoma cell lines. (A) WM266 (left panel), WM115 (middle panel) and LOX IMVI (right panel) melanoma cells were starved and then treated with BRAFi $(0.5 \mu \mathrm{M}$ ) for different times (from $2 \mathrm{~h}$ to $72 \mathrm{~h}$ ). ErbB3/Akt axis is early activated after BRAF inhibitor treatments with a different manner. Densitometric analysis values were used to evaluate $\mathrm{pErbB3/ErbB3,} \mathrm{pERK/ERK} \mathrm{and} \mathrm{pAkt/Akt} \mathrm{expression} \mathrm{with} \mathrm{respect} \mathrm{to} \mathrm{the} \mathrm{control} \mathrm{untreated}$ cells. (B) In the same experimantal condition (panel A) also total RNA was extracted and subjected to qRT-PCR in order to evaluate the kinetic activation of of NRG1, ErbB3 and FOXD3 genes. Results are represented as a "heat map". Colors in the heat map indicate no increase in gene expression (green); moderate increase (yellow) or a strong increase (red), respectively. GAPDH reference gene was used for normalization.

\subsection{NRG-1 Activation Occurs via Different Mechanisms}

Based on previous results we decided to focus our attention on two melanoma cell lines, namely WM266 and WM115, which show early and intermediate times of NRG-1 up-regulation upon BRAF inhibition respectively. In particular, we decided to investigate whether the increase of NRG-1 mRNA could be related to increased gene transcription. To this purpose we used a human NRG1 promoter-luciferase reporter construct (pGL3-NRG1) previously described by Zhang et al. [23]. pGL3-NRG1 contains two distinct promoter regions from nucleotide -3987 to -3644 and from nucleotide -777 to +193 relative to the CAP site and is dependent upon Notch activation. Melanoma cells were transfected with pGL3-NRG1, exposed or not to vemurafenib. Cell extracts were prepared and assayed for luciferase activity. The results (Figure 4A) show that while in WM115 promoter activity is increased several-fold after BRAF inhibitor treatment (Figure 4A right panel), in WM266 cells there is no drug-induced promoter activation (Figure 4A left panel). Moreover the same experiments were performed also in A375 cells which have not shown a significant increased promoter activity after BRAF inhibitor treatment as observed in WM266 cell line (Figure S7). This result has been observed in at least three separate experiments. These findings support the notion that NRG-1 
activation may be due to different mechanisms in the two cell lines, i.e., transcriptional in WM115 and post-transcriptional in WM266. To confirm this WM115 and WM266 cells were exposed to vemurafenib as BRAF inhibitor and co-treated with actinomycin D, a known inhibitor of RNA polymerase. Total RNA was extracted $24 \mathrm{~h}$ after BRAFi exposure. Quantitative RT-PCR analysis were performed on NRG-1 and ErbB3 mRNAs. This confirmed (Figure 4B) that after treatment for $24 \mathrm{~h}$ with BRAF inhibitor alone, NRG-1 but not ErbB3 was strongly induced in both WM266 and in WM115. When WM115 cells were co-treated with BRAF inhibitor and actinomicin D, upregulation of NRG-1 mRNA levels was totally inhibited (Figure 4B right panel). This result is in line with the upregulation of promoter-driven luciferase expression shown above and confirms the notion that in this cell line increased neuregulin expression is under transcriptional control. In contrast, in WM266 cells NRG-1 mRNA levels were not decreased by simultaneous exposure to Actinomycin D (Figure 4B left panel). This result suggests that in this cell line NRG-1 upregulation following drug exposure is not under transcriptional control.

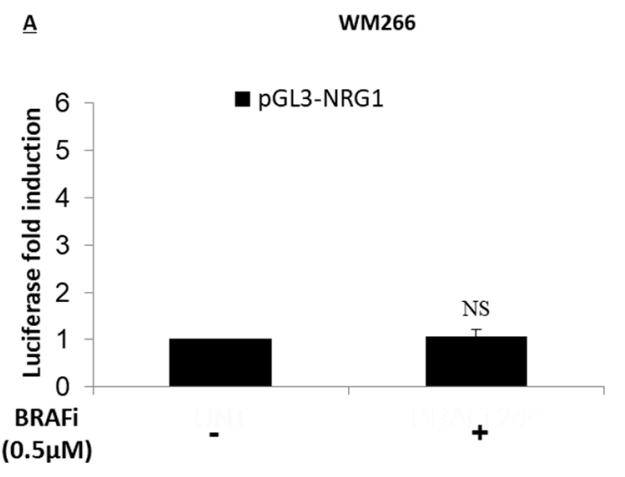

$\underline{B}$

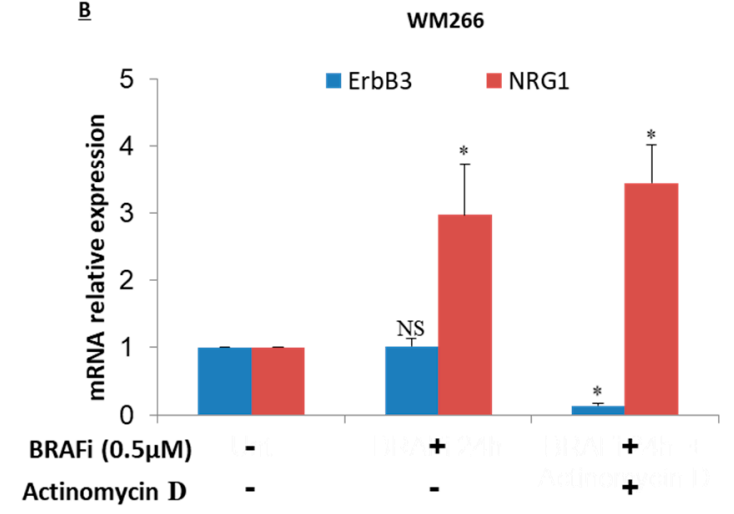

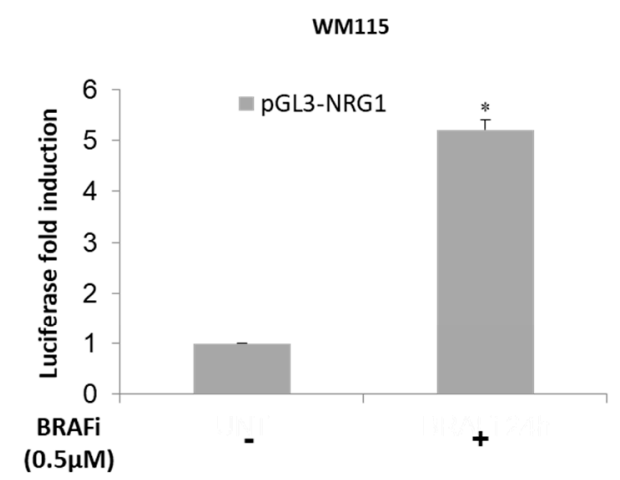

WM115

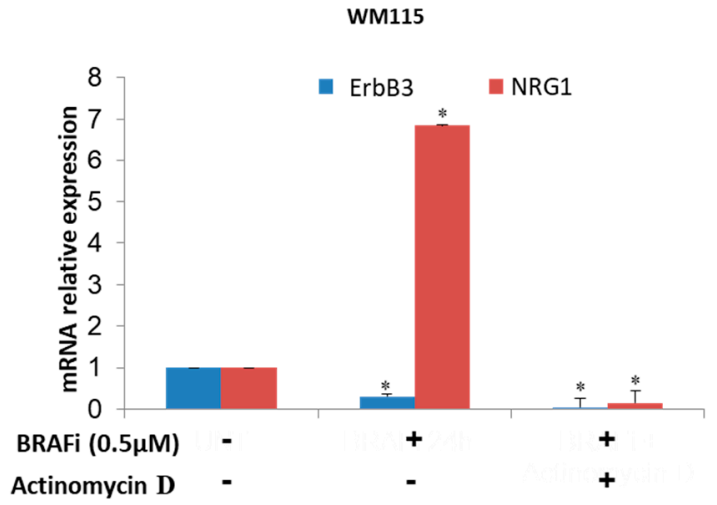

Figure 4. WM266 and WM115 melanoma cells show different mechanisms of NRG-1 activation. (A) WM266 and WM115 cells were transfected with NRG1-reporter plasmid and treated or not with BRAF inhibitor to $0.5 \mu \mathrm{M}$ for $24 \mathrm{~h}$. The luciferase gene was cloned downstream of NRG1. The luciferase activity was evaluated by the Renilla Luciferase assay. The results show that NRG1 gene promoter activity is enhanced after BRAF inhibitor treatment only in WM115 cells while no luciferase induction occurred in WM266 cell line. (B) Melanoma cells were co-treated with BRAF inhibitor $(0.5 \mu \mathrm{M})$ and actinomicin D transcription inhibitor $(5 \mu \mathrm{g} / \mathrm{mL})$ for $24 \mathrm{~h}$ and subsequently collected and subjected to qRT-PCR analysis to evaluate ErbB3 and NRG1 gene expression. Results show that only in WM115 cells NRG1 expression is under transcriptional control. GAPDH reference gene was used for normalization. *: $p<0.05$. NS: $p>0.05$.

\section{5. pErbB3 Upregulation Is Observed in Circulating Melanoma Cells After Treatment with MAPK Inhibitors}

In order to assess if neuregulin-induced pErbB3 activation occurs also in the clinical setting we decided to carry out a clinical study in BRAF mutated melanoma patients undergoing standard dual therapy with MAPK inhibitors. To this purpose we focused our attention on Circulating Tumor Cells (CTCs). CTCs are cells that derive from the tumour bulk but are capable of spreading throughout the 
body because after the detachment from primary tumour sites, are able to resist programmed cell death (a phenomenon also known as "anoikis"). Evidence of the biological and clinical significance of CTCs is rapidly increasing. The use of the standardized systems to detect rare tumour cells in the blood of patients with a variety of tumours has facilitated the enumeration of CTCs and their monitoring over time [24-26]. Furthermore, fluorescent staining of isolated CTCs may allow some level of functional analysis. In recent years the study of CTCs in melanoma has been proposed as tool for the surveillance of metastatic melanoma patients [27] and has been also shown to be helpful to better understand clonal heterogeneity in melanoma [28].

In the present study we enrolled a total of 11 BRAF-mutated metastatic melanoma patients. Patients characteristics are reported in Table S1. Blood samples were collected before initiation of therapy with BRAF and MEK inhibitors and after short term. Samples were processed as described in the materials and methods section and CTCs were collected on membrane filters (Figure 5A). Filters were subjected to an immunofluorescence assay using a specific staining to identify the expression of the phosphorylated ErbB3 receptor (Figure 5B and Figure S8). Further images in which the activation of pErbB3 was detected in CTCs of melanoma patients after MAPKi treatment are reported in Figure S9A. A technical note about these data: both DAPI dye and antibody used to stain cell nuclei and pErbB3 respectively, can remain trapped in the pores causing their coloring by autofluorescence. In addition since leucocytes can be present in the filter because their size is larger than that of the pores a specific staining for CD45 was performed in order to distinguish them from CTCs (Figure S9B). In our samples we observed a very low proportion of white cells. As expected CTCs not showed the expression of CD45 receptor as compared to leucocytes (Figure S9B) $[29,30]$.

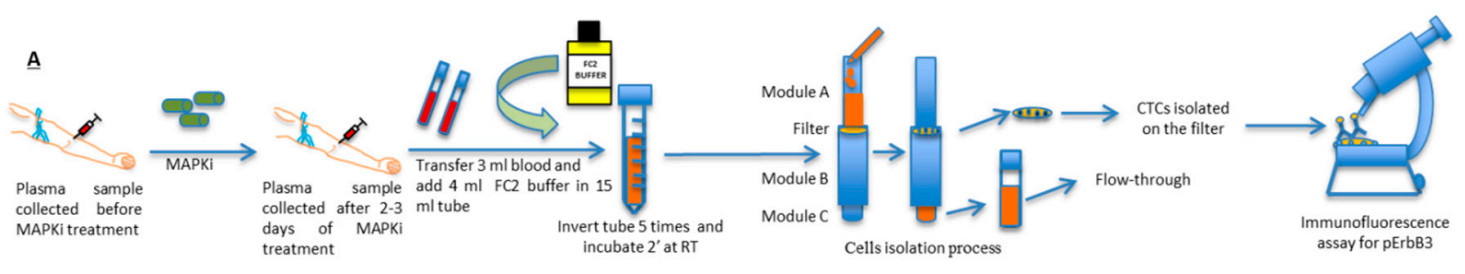

$\underline{B}$
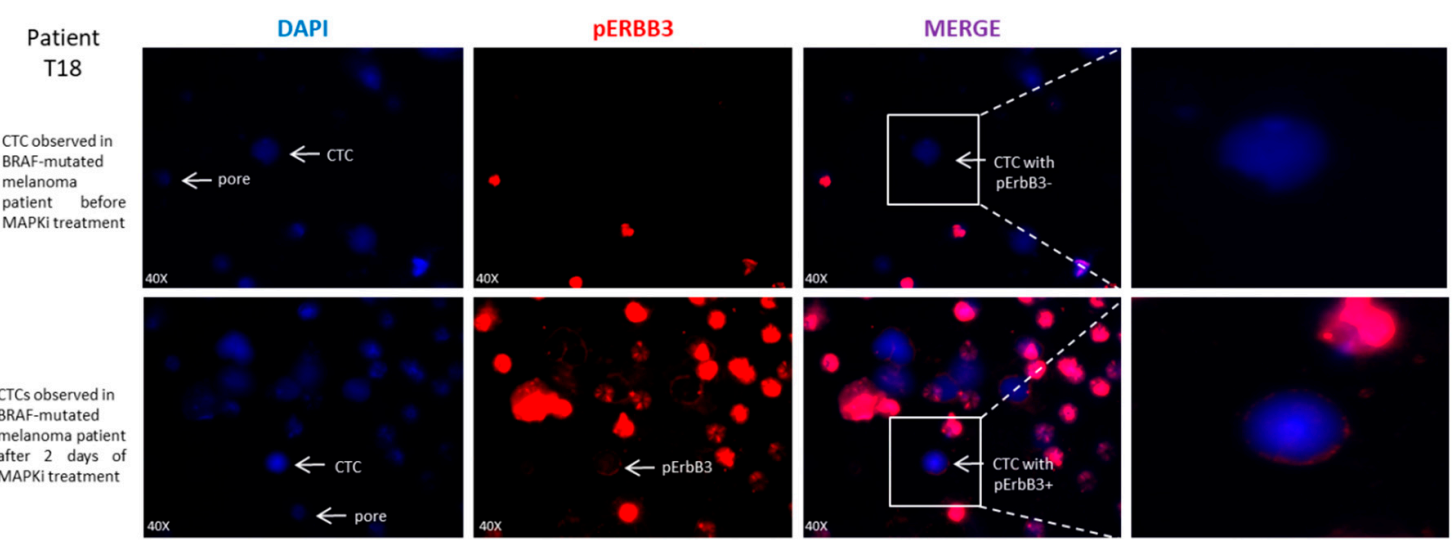

Figure 5. ErbB3 activation is observed in circulating melanoma cells after short term treatment with MAPK inhibitors. (A) Schematic representation A shows all steps to isolate the circulating tumor cells (CTCs) from plasma samples of the 11 metastatic melanoma patients before and after short term treatment with MAPK inhibitors. (B) CTCs isolated by CELLSEARCH ${ }^{\circledR}$ Circulating Tumor Cell Kit are subjected to Immunofluorescence analysis in order to evaluate pErbB3 activation through pimary pErbB3 antibody and secondary Anti-Texas Red Antibody. T18 melanoma patient shows the activation of phospho-ErbB3 receptor after 2 days of MAPKi treatment in circulating tumor cells (CTC with pErbB3+) $($ Dapi $=$ CTCs nuclei; Red $=$ pErbB3). Scale bars: $50 \mu \mathrm{m}$. 
Results are reported in Figure 6 and Table S2. They show that in BRAF-mutated melanoma patients after 3 days of treatment with BRAF and MEK inhibitors there is a statistically significant increase in the number of CTCs bearing activated $\mathrm{pErbB3}$ receptor as compared to CTCs before initiation of treatment (Figure 6A). Of note, in some cases, the activation of the pErbB3 receptor was observed only after the treatment. In addition, in eight patients out of 11 we observed an increased activation of ErbB3 receptor (Figure 6B). Data were also used to plot the Receiver Operating Characteristic (ROC) curve (Figure 6C) which indicates that ErbB3 phosphorylation describes the treatment with MAPK inhibitors with a significant AUC of 0.70 .

A

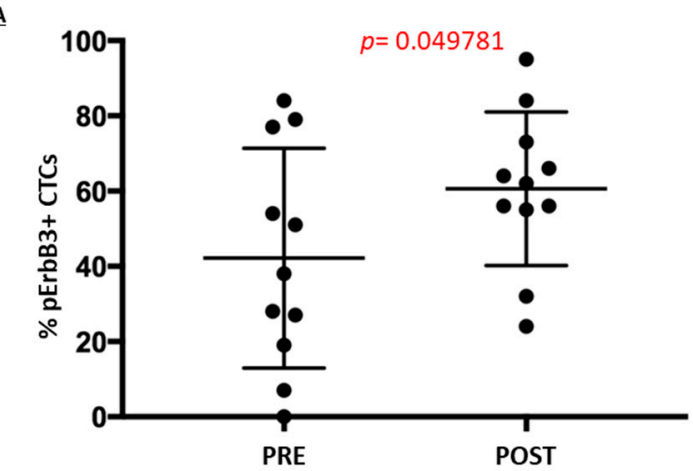

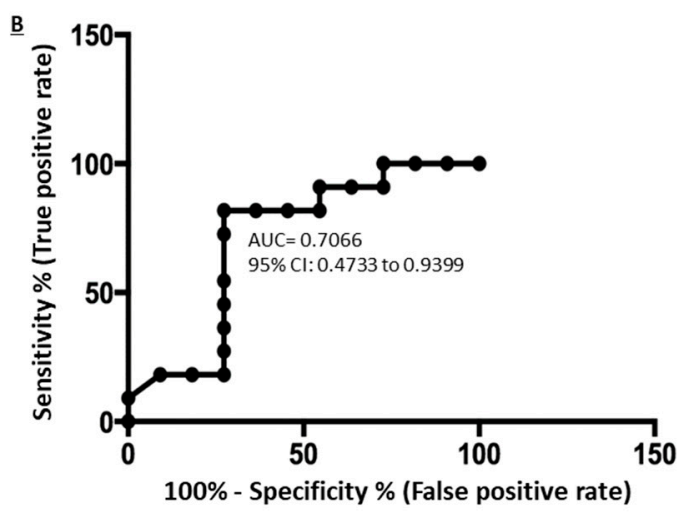

$\underline{\mathbf{C}}$

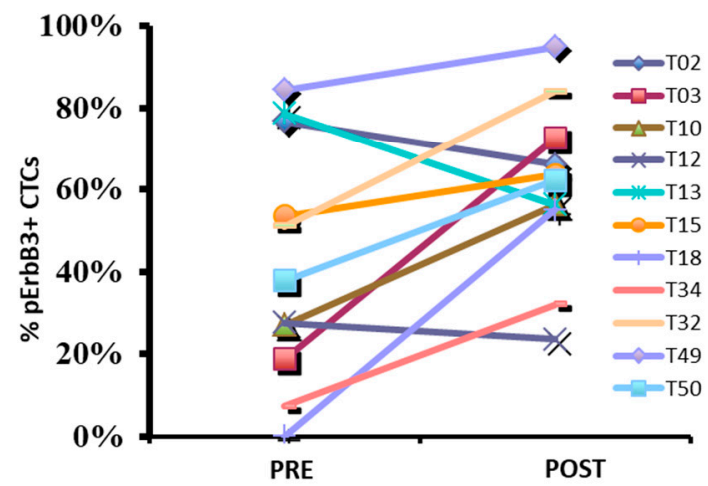

Figure 6. Statistical analysis. (A) Box-plot graph was obtained by GraphPad Prism software. Results show that the percentage of phospho-ErbB3 results to be activated greater in CTC's melanoma patients upon treatment with MAPKi $(p<0.05)$. $p$ value was calculated using the $t$-test whose significance is expressed as $p<0.05$. (B) The second panel depicts the individual patients' analysis to evaluate ErbB3 receptor activation before and after short term MAPK inhibitor treatment. (C) Receiver operating characteristic (ROC) curves estimating the predictive value of ErbB3 activation as early marker upon treatment with MAPK inhibitors.

\section{Discussion}

The NRG1/ErbB3/AKT axis has been shown to be involved in adaptive drug resistance in several tumour types, including, breast, lung, prostate, cancer and melanoma [11,12,16,31-35]. Cancer cells of different origin, when exposed to standard chemo- or target-therapy promptly react through the activation of a common survival pathway centred around the EGFR receptor family member ErbB3 and its downstream signalling elements PI3K and AKT. The high frequency with which this particular pathway is activated in adaptive resistance is justified by its intrinsically high transducing capacity which is due to the strong processivity of the kinase domain of ErbB3 common dimerization partner HER2/ErbB2 and to the presence in the intracytoplasmic domain of ErBB3 of several Tyr residues substrates for phosphorylation as docking sites for PI3K (ErbB3) [18]. 
The most common ligand of the ErbB2/ErbB3 heterodimer is NRG1 despite several other members of the Neuregulin family have been found to be involved in its activation. These proteins derive from the alternative splicing of four genes giving rise to at least 26 different isoforms [36]. However NRG1 is described as the major ligand involved in drug resistance mediated by ErbB2/ErbB3 heterodimer activation. A group of studies, mostly in melanoma but also in breast and thyroid cancer, linked NRG1-induced ErbB3 activation to a paracrine effect and to a remodelling of the tumour microenvironment following exposure to BRAF and MEK inhibitors involving stromal fibroblasts as the main source of NRG-1 mediated PI3k/AKT activation [4,20,37,38]. In other cases NRG1 was shown to be produced by the same tumour cells and to induce ErbB3 phosphorylation via an autocrine lop [16]. We have previously proposed this last mechanism to be active also in melanoma [19]. In order to assess in greater detail this aspect we conducted the present study in a panel of V600 BRAF-mutated human melanoma cell lines and utilizing a combination of approaches involving the use of conditioned medium from BRAFi exposed cells and of neutralizing antibodies against NRG1. All these approaches confirmed the validity of the autocrine loop model, the most compelling proof of this was the demonstration that antibodies against NRG1 synergize with a BRAFi in the inhibition of melanoma cell growth in the absence of exogenously added NRG1. In summary we believe that at least in melanoma, when cells are exposed to targeted therapy, redundant cell autonomous and non- cell autonomous mechanisms are activated leading to the production of NRG1 by both melanoma cells and cells of the tumour microenvironment which converge into the activation of the ErbB3/PI3K/AKT pathway.

It has been previously shown that the transcription factor FOXD3 is rapidly induced in melanoma cells upon inhibition of MAPK signalling and that this phenomenon contributes to adaptive resistance to RAF inhibitors also in part through enhanced transcription of the ErbB3 receptor gene [22]. More recently FOXD3 activation has been attributed to sumoylation of transcription factor SOX10 which is inhibited by ERK activity [39]. Interestingly our data confirm in all BRAF mutated melanoma cell lines analysed that FOXD3 mRNA is upregulated, however it never precedes temporally upregulation of NRG1, which, to our opinion, remains therefore the principal driver of adaptive resistance to BRAF and MEK inhibitors.

Our study reveals that a variety of mechanisms can be a basis of NRG1 upregulation. In support of this concept we demonstrated thanks to a combination of transfection experiments with a hybrid promoter construct and of transcription inhibition assays that, while in WM115 cells NRG1 is transcriptionally upregulated, in WM266 a post-transcriptional mechanism must be at play. We have been unable so far to identify this last mechanism. We can only exclude at this time that this is due to increased mRNA stability consequent to decreased levels of miRNA-548 which was postulated through TargetScanHuman bioinformatic analysis (http://www.targetscan.org/vert_72/) [40] as a potential binder of the NRG1 mRNA $3^{\prime}$ untranslated region. However, these are not the only possible mechanisms that can be responsible for NRG1 upregulation. Indeed Ebbing et al. previously showed in a gastroesophegeal cancer model that resistance to trastuzumab was caused by increased release of surface heregulin following upregulation of metalloprotease ADAM10 [41]. With regard to the transcriptional activation observed in WM115 cells following cell exposure to MAPK inhibitors, a potential explanation could be the activation of Notch pathway in which factor Notch1 directly regulates the transcription of neuregulin by binding to its promoter region contributing in this way to melanoma tumorigenicity [23,42-44].

The involvement of ErbB3 in the development of drug resistance has been shown so far only in in vitro or in vivo pre-clinical models. A demonstration that this mechanism could be active also in the clinic had been missing. We have tried to fill this gap of knowledge by addressing the question of whether increased ErbB3 phosphorylation takes place also in patients soon after initiation of therapy with MAPK inhibitors. We decided to follow a non-invasive approach directed to analyse by immunofluorescence the phosphorylation status of the ErbB3 receptor in CTCs isolated from BRAF mutated melanoma patients before the initiation of therapy and 3 days after the start of therapy. The results, albeit obtained from a small number $(n=11)$ of patients, show a statistically significant 
increase of ErbB3 specific phosphorylation in circulating melanoma cells. In other types of tumours such as ovarian cancer and glioblastoma the expression of ErbB3 receptor had been detected before in CTCs [24]. For the first time we identified the presence of phospho-ErbB3 receptor in CTCs isolated from human melanoma plasma samples. Our data suggest that also melanomas activate the ErbB3 receptor soon after exposure to MAPK inhibitors probably through NRG1 overexpression in order to counteract the anti-proliferative effect of targeted therapy. Activation of ErbB3 receptor in CTCs in response to MAPK inhibitor treatments, could help promoting survival and metastatization of circulating malignant melanoma in other locations of the body.

\section{Materials and Methods}

\subsection{Cell Lines and Treatments}

Human melanoma cell lines, WM266, LOX IMVI, M14, A375 and WM115 were cultured in RPMI supplemented with $10 \%$ FBS. To evaluate ErbB3, AKT and ERK 1/2 signalling melanoma cells were seeded and the following day they were serum starved overnight. Afterwards cells were exposed to vemurafenib for the indicated time points $(2,8$ and $24 \mathrm{~h})$. Conditioned medium $(\mathrm{CM})$ was collected at each time point and transferred to treatment naive serum starved melanoma cells for $30 \mathrm{~min}$. Differently melanoma cells were also treated from $2 \mathrm{~h}$ to $72 \mathrm{~h}$ in order to study the activation kinetics of the ErbB3/Akt axis by western blotting assay. BRAF-mutated human melanoma cell lines, LOX IMVI, A375, M14 (V600E), WM115, WM266 (V600D) were obtained from the laboratory of Dr. Paolo A. Ascierto at National Cancer Institute of Naples “Fondazione G. Pascale”, Naples, Italy.

\subsection{Antibodies and Reagents}

Antibodies for western blotting analyses were purchased from Cell Signaling Technology (Boston, MA, USA). Anti-ErbB3 and anti-GAPDH were obtained from Santa Cruz Biotechnology (Dallas, TX, USA) [13,17]. Anti-rabbit and anti-mouse were purchased from AbCam (Cambridge, UK). Vemurafenib and trametinib were obtained from Selleck Chemicals (Houston, TX, USA). TaqMan probes for ErbB3, HRG, FOXD3 and housekeeping gene GAPDH were purchased from Applied Biosystems (Foster City, CA, USA). Actinomycin D was purchased from Sigma (St. Louis, MO, USA). The anti-NRG (blocking peptide) was purchased from Thermo Fisher Scientific (Waltham, MA, USA). Immunofluorescence primary antibody phospho-ErbB3 was obtained from Santa Cruz Biotechnology.

\subsection{NRG-1 Detection}

Released NRG-1 in cell culture media was detected by an immunoassay through Bio-Plex system Bio-Rad (Hercules, CA, USA) according to manufacturer's instructions. Briefly, laser excitation is used to determine NRG-1 concentration by measuring the reporter dye fluorescence and fluorescence signal is in direct proportion to the amount of NRG-1 bound.

\subsection{Western Blot Analysis}

Melanoma cells were lysed with RIPA buffer; $50 \mu \mathrm{g}$ of total protein were resolved under reducing conditions by $8 \%$ SDS-PAGE [45]. The membranes were blocked with $5 \%$ non fat dry milk in PBS $0.1 \%$ Tween 20, and incubated with the different primary antibodies. GAPDH and Vinculin were used to estimate the protein equal loading. Densitometric analysis was performed using Quantity One Program (Hercules, CA, USA).

\subsection{RNA Extraction and Real-Time PCR Analysis}

RNA was extracted using TRIzol method (Thermo Fisher Scientific) [46] according to manufacturer's instruction. Total RNA was quantitated by spectrophotometry. Real Time-PCR was assayed by TaqMan Gene Expression Assays (Applied Biosystems). Each targeted transcript was 
validated using the comparative $\mathrm{Ct}$ method for relative quantification $(\Delta \Delta \mathrm{Ct})$ reference to the amount of a common reference gene (GAPDH) [46].

\subsection{Luciferase Assays}

The NRG1-reporter plasmid was provided by B. Bedogni [23]. Melanoma cells were transfected using the Lipofectamine 2000 (Thermo Fisher Scientific) according to the manufacturer's instructions. After $48 \mathrm{~h}$, cells were lysed in $100 \mu \mathrm{L}$ lysis buffer (Promega, Madison, WI, USA). Activities of Firefly and Renilla were assessed by the dual-luciferase Assay system (Promega) and light production was measured for $10 \mathrm{~s}$ in GloMax-Multi Detection System (Promega).

\subsection{Cell Viability}

The number of viable melanoma cells was mesured by quantification of the ATP present according to CellTiter-Glo ${ }^{\circledR}$ Luminescent Cell Viability assay protocol. WM266 melanoma cells were seeded in a 96 multiwell plate and trated with different doses of BRAF inhibitor together to peptide anti-NRG1 (the inefficient A2 antibody against ErbB3 was used as control). Colony formation assays have been performed as previously described [47,48].

\subsection{Patient Selection}

The use of human samples was approved by Istituto Pascale's Ethical Committee with the protocol DSC/1504 on June 11, 2014. Patients eligible for inclusion in this study have all the following criteria:

(1) Patients $\geq 18$ years old.

(2) Patients able to understand and willing to sign the informed consent form and able to adhere to the study visit scheme and other protocol requirements. Written informed consent must be obtained before any procedure.

(3) Diagnosis confirmed by locally advanced stage melanoma histology or metastatic (stage IIIB-IV according to the American Joint Committee on Cancer-AJCC).

(4) The patient is a candidate for therapy with BRAF inhibitors and/or MEK inhibitors.

\subsection{Circulating Tumor Cells (CTCs) Isolation}

ScreenCell ${ }^{\circledR}$ size exclusion technology was used (see Figure $5 \mathrm{~A}$ ) to isolate circulating tumor cells. In particular melanoma patients' blood samples were collected in a K2-EDTA tubes Patients' blood samples were collected in aK2-EDTA tubes. The screenCell FC2 buffer was prepared bringing it to the optimal $\mathrm{pH}$ (pH between 6.7 and 7) through the use of $\mathrm{NaOH}$. Then $3 \mathrm{~mL}$ of blood and $4 \mathrm{~mL}$ of screenCell FC2 buffer were added into a sterile $15 \mathrm{~mL}$ tube and mixed together by inverting the tube. Incubate for $8 \mathrm{~min}$ at room temperature. At this point the solution was located in the upper part of the ScreenCell cyto device which in detail consists of a column (module A) and a vacuum tube (module $\mathrm{B}$ ) inserted in the lower part (module $\mathrm{C}$ ). The negative pressure released will allow the passage of solution through the filter located between the lower part of the column (module A) and the module B. The filtered blood was collected in the vacuum tube (module C). When the solution (blood + buffer) was about to end, $1.6 \mathrm{~mL}$ of PBS was added in order to wash the filter. At the end of the process the filter was recovered leaving it to dry on absorbent paper for an hour and then processed by immunofluorescence or stored at $-20^{\circ} \mathrm{C}$.

\subsection{Immunofluorescence}

Each filter was rinsed with 100 microliters of PBS for $10 \mathrm{~min}$. Later 100 microliters of the "blocking solution" composed of 10\% BSA, 100\% Triton and 100\% FBS were used for $1 \mathrm{~h}$ at room temperature. Then two more PBS washes were made again before using a 10\% BSA solution, 100\% Triton where the primary antibody is diluted 1:50. Of the following solution 100 microliters per well were used for $1 \mathrm{~h}$ at $37^{\circ} \mathrm{C}$. After that a couple of PBS washes were done, the secondary antibody was used for 
$40 \mathrm{~min}$ at $4{ }^{\circ} \mathrm{C}$. Finally, nuclear staining was performed with the DAPI diluted 1:1000 for $5 \mathrm{~min}$ at room temperature before reading with the fluorescence.

\subsection{Statistical Analyses}

All results reported in this manuscript are presented as mean values from three independent experiments \pm S.D. ROC curves have been plotted as previously described [47]. Quantitative analysis for curve fitting have been performed through KaleidaGraph software (version 4.1; Synergy Software, Reading, PA, USA) [19].

\section{Conclusions}

Our study further underscores the importance of non-mutational adaptive mechanism of resistance to target therapy in metastatic melanoma. This has significant implications for the development of more powerful combination therapies capable to provide a longer-term control of disease. In the last year a plethora of promising non mutational mechanisms have been discovered which involve both intracellular proteins [2,49] and non-coding RNAs [47,48,50-52] which are waiting for testing in the clinical setting.

The development of biological assays such as the one we have shown here in CTCs may help to guide the development of new therapeutic combinations. In fact, our new findings could have potential diagnostic implications in the field of liquid biopsy, as the activation of the ErbB3-NRG1 axis could be implicated as a new early biomarker able to predict the response to the targeted therapies in metastatic melanoma patients. It will be interesting in the future to confirm these data in a larger cohort of patients and to establish a possible correlation between early (and perhaps more pronounced) activation of pErbB3 in melanoma CTCs and clinical outcome.

Supplementary Materials: The following are available online at http://www.mdpi.com/2072-6694/11/10/1425/s1, Figure S1: Whole blot of Figure 1B, Figure S2: Secretion of NRG1 from WM266 cell media, Figure S3: Whole blot of Figure 2B, Figure S4: Colony formation assays, Figure S5: Whole blot of Figure 3A, Figure S6: qRT-PCR of NRG-1, ErbB3 and FOXD genes upon BRAFi exposure, Figure S7: Luciferase assay, Figure S8: CTCs and pErbB3 revelation, Figure S9: Immunofluorescence analyses for CD45 expression and activation of pErbB3 in CTCs, Table S1: Clinical features of the 11 melanoma patients, Table S2: CTCs + pErbB3 count.

Author Contributions: C.F.R., D.M., L.F., D.L. and V.S. materially executed all the in vitro studies with melanoma cells, i.e., melanoma cell cultures, protein extraction, western blotting, cell proliferation assays, inhibition with BRAF inhibitors and with antibodies against NRG1. D.M. carried out transfection assays and luciferase assays with NRG1 promoter fusions. C.F.R. and D.M. performed analysis of melanoma CTCs on membrane filters through immunofluorescence assays. G.M., D.M., M.C. and V.V. recruited melanoma patients in the clinical study of melanoma CTCs, collected blood and separated CTCs on filters. B.B. provided the NRG1 luciferase promoter construct and suggestions about transfection studies in melanoma cells. C.F.R. assembled all the data in this manuscript. P.A.A., R.M. and G.C. coordinated the study and revised the manuscript.

Funding: This work was supported by AIRC grant IG 15216 to G. Ciliberto; RM was supported by AIRC grant IG IG17009 and the Lazioinova grant 2018 n.85-2017-13750; LF was supported by AIRC/FIRC fellowship and is a recipient of a fellowship granted by Istituto Pasteur Italia- Fondazione Cenci Bolognetti; C.F.R. is a recipient of a fellowship by Intergruppo Melanoma Italiano (IMI).

Acknowledgments: G.C. wishes to dedicate this paper to the memory of Giovanni Morrone who for several years has been the coordinator of the PhD course of Oncology at the University of Catanzaro and has followed closely the activities of Debora Malpicci and Ciro Francesco Ruggiero during their PhD thesis work.

Conflicts of Interest: All The authors declare no conflict of interest with the exception of P.A.A. P.A.A. has advisory/consultant role for BMS, Roche-Genentech, MSD, Array, Novartis, Merck Serono, Pierre Fabre, Incyte, Genmab, Newlink Genetics, Medimmune, AstraZeneca, Syndax, Sun Pharma, Sanofi, Idera, Ultimovacs, Sandoz, Immunocore, 4SC. P.A.A. receives research funds from BMS, Roche-Genentech, Array and travel support from MSD. The funders of this study had no role in the design of the study; in the collection, analyses, or interpretation of data; in the writing of the manuscript, or in the decision to publish the results. 


\section{References}

1. Ryška, A.; Horký, O.; Berkovcová, J.; Tichá, I.; Kalinová, M.; Matějčková, M.; Bóday, A.; Drábek, J.; Martínek, P.; Šimová, J.; et al. Malignant Melanoma-From Classical Histology towards Molecular Genetic Testing. Klin. Onkol. 2017, 30, 182-189. [PubMed]

2. Luke, J.J.; Flaherty, K.T.; Ribas, A.; Long, G.V. Targeted agents and immunotherapies: Optimizing outcomes in melanoma. Nat. Rev. Clin. Oncol. 2017, 14, 463-482. [PubMed]

3. Mason, R.; Au, L.; Ingles Garces, A.; Larkin, J. Current and emerging systemic therapies for cutaneous metastatic melanoma. Expert Opin. Pharmacother. 2019, 20, 1135-1152. [CrossRef] [PubMed]

4. Cheng, L.; Lopez-Beltran, A.; Massari, F.; Maclennan, G.T.; Montironi, R. Molecular testing for BRAF mutations to inform melanoma treatment decisions: A move toward precision medicine. Mod. Pathol. 2018, 31, 24-38. [CrossRef] [PubMed]

5. Arozarena, I.; Wellbrock, C. Overcoming resistance to BRAF inhibitors. Ann. Transl. Med. 2017, 5, 387. [CrossRef] [PubMed]

6. $\quad$ Long, G.V.; Eroglu, Z.; Infante, J.; Patel, S.; Daud, A.; Johnson, D.B.; Gonzalez, R.; Kefford, R.; Hamid, O.; Schuchter, L.; et al. Long-term outcomes in patients with BRAF V600-mutant metastatic melanoma who received dabrafenib combined with trametinib. J. Clin. Oncol. 2018, 36, 667-673. [PubMed]

7. Lim, S.Y.; Menzies, A.M.; Rizos, H. Mechanisms and strategies to overcome resistance to molecularly targeted therapy for melanoma. Cancer 2017, 123, 2118-2129. [CrossRef]

8. Belleudi, F.; Marra, E.; Mazzetta, F.; Fattore, L.; Giovagnoli, M.R.; Mancini, R.; Aurisicchio, L.; Torrisi, M.R.; Ciliberto, G. Monoclonal antibody-induced ErbB3 receptor internalization and degradation inhibits growth and migration of human melanoma cells. Cell Cycle 2012, 11, 1455-1467.

9. Ma, J.; Lyu, H.; Huang, J.; Liu, B. Targeting of erbB3 receptor to overcome resistance in cancer treatment. Mol. Cancer 2014, 13, 108. [CrossRef]

10. Noto, A.; De Vitis, C.; Roscilli, G.; Fattore, L.; Malpicci, D.; Marra, E.; Luberto, L.; D'Andrilli, A.; Coluccia, P.; Giovagnoli, M.R.; et al. Combination therapy with anti-ErbB3 monoclonal antibodies and EGFR TKIs potently inhibits Non-small Cell Lung Cancer. Oncotarget 2013, 4, 1253-1265. [CrossRef]

11. Nonagase, Y.; Yonesaka, K.; Kawakami, H.; Watanabe, S.; Haratani, K.; Takahama, T.; Takegawa, N.; Ueda, H.; Tanizaki, J.; Hayashi, H.; et al. Heregulin-expressing HER2-positive breast and gastric cancer exhibited heterogeneous susceptibility to the anti-HER2 agents lapatinib, trastuzumab and T-DM1. Oncotarget 2016, 7, 84860-84871. [PubMed]

12. Poovassery, J.S.; Kang, J.C.; Kim, D.; Ober, R.J.; Ward, E.S. Antibody targeting of HER2/HER3 signaling overcomes heregulin-induced resistance to PI3K inhibition in prostate cancer. Int. J. Cancer 2015, 137, $267-277$. [CrossRef]

13. Tiwary, S.; Preziosi, M.; Rothberg, P.G.; Zeitouni, N.; Corson, N.; Xu, L. ERBB3 is required for metastasis formation of melanoma cells. Oncogenesis 2014, 3, e110. [CrossRef]

14. Reschke, M.; Mihic-Probst, D.; Der Van Horst, E.H.; Knyazev, P.; Wild, P.J.; Hutterer, M.; Meyer, S.; Dummer, R.; Moch, H.; Ullrich, A. HER3 Is a determinant for poor prognosis in melanoma. Clin. Cancer Res. 2008, 14, 5188-5197.

15. Fattore, L.; Malpicci, D.; Marra, E.; Belleudi, F.; Noto, A.; De Vitis, C.; Pisanu, M.E.; Coluccia, P.; Camerlingo, R.; Roscilli, G.; et al. Combination of antibodies directed against different ErbB3 surface epitopes prevents the establishment of resistance to BRAF/MEK inhibitors in melanoma. Oncotarget 2015, 6, 24823-24841. [CrossRef]

16. Prasetyanti, P.R.; Capone, E.; Barcaroli, D.; D’Agostino, D.; Volpe, S.; Benfante, A.; van Hooff, S.; Iacobelli, V.; Rossi, C.; Iacobelli, S.; et al. ErbB-3 activation by NRG-1 $\beta$ sustains growth and promotes vemurafenib resistance in BRAF-V600E colon cancer stem cells (CSCs). Oncotarget 2015, 6, 16902-16911. [PubMed]

17. Yang, L.; Li, Y.; Shen, E.; Cao, F.; Li, L.; Li, X.; Wang, X.; Kariminia, S.; Chang, B.; Li, H.; et al. NRG1-dependent activation of HER3 induces primary resistance to trastuzumab in HER2-overexpressing breast cancer cells. Int. J. Oncol. 2017, 51, 1553-1562. [PubMed]

18. Van Lengerich, B.; Agnew, C.; Puchner, E.M.; Huang, B.; Jura, N. EGF and NRG induce phosphorylation of HER3/ERBB3 by EGFR using distinct oligomeric mechanisms. Proc. Natl. Acad. Sci. USA 2017, 114, E2836-E2845. [PubMed] 
19. Fattore, L.; Marra, E.; Pisanu, M.E.; Noto, A.; de Vitis, C.; Belleudi, F.; Aurisicchio, L.; Mancini, R.; Torrisi, M.R.; Ascierto, P.A.; et al. Activation of an early feedback survival loop involving phospho-ErbB3 is a general response of melanoma cells to RAF/MEK inhibition and is abrogated by anti-ErbB3 antibodies. J. Transl. Med. 2013, 11, 180. [CrossRef]

20. Capparelli, C.; Rosenbaum, S.; Berger, A.C.; Aplin, A.E. Fibroblast-derived neuregulin 1 promotes Compensatory ErbB3 receptor signaling in mutant BRAF melanoma. J. Biol. Chem. 2015, 290, 24267-24277. [PubMed]

21. Capparelli, C.; Rosenbaum, S.; Berman-Booty, L.D.; Salhi, A.; Gaborit, N.; Zhan, T.; Chervoneva, I.; Roszik, J.; Woodman, S.E.; Davies, M.A.; et al. ErbB3-ErbB2 complexes as a therapeutic target in a subset of wild-type BRAF/NRAS cutaneous melanomas. Cancer Res. 2015, 75, 3554-3567. [CrossRef] [PubMed]

22. Abel, E.V.; Basile, K.J.; Kugel, C.H.; Witkiewicz, A.K.; Le, K.; Amaravadi, R.K.; Karakousis, G.C.; Xu, X.; Xu, W.; Schuchter, L.M.; et al. Melanoma adapts to RAF/MEK inhibitors through FOXD3-mediated upregulation of ERBB3. J. Clin. Investig. 2013, 123, 4609-4618.

23. Zhang, K.; Wong, P.; Zhang, L.; Jacobs, B.; Borden, E.C.; Aster, J.C.; Bedogni, B. A Notch1neuregulin1 autocrine signaling loop contributes to melanoma growth. Oncogene 2012, 31, 4609-4618. [PubMed]

24. Geethadevi, A.; Parashar, D.; Bishop, E.; Pradeep, S.; Chaluvally-Raghavan, P. ERBB signaling in CTCs of ovarian cancer and glioblastoma. Genes Cancer 2017, 8, 746-751.

25. Fabisiewicz, A.; Grzybowska, E. CTC clusters in cancer progression and metastasis. Med. Oncol. 2017, 34, 12. [CrossRef] [PubMed]

26. Bidard, F.C.; Proudhon, C.; Pierga, J.Y. Circulating tumor cells in breast cancer. Mol. Oncol. 2016, 10, 418-430.

27. Huang, S.K.; Hoon, D.S.B. Liquid biopsy utility for the surveillance of cutaneous malignant melanoma patients. Mol. Oncol. 2016, 10, 450-463.

28. Scaini, M.C.; Pigozzo, J.; Pizzi, M.; Manicone, M.; Chiarion-Sileni, V.; Zambenedetti, P.; Rugge, M.; Zanovello, P.; Rossi, E.; Zamarchi, R.; et al. Clonal heterogeneity of melanoma in a paradigmatic case study. Melanoma Res. 2019, 29, 189-194.

29. Nicolazzo, C.; Colangelo, L.; Corsi, A.; Carpino, G.; Gradilone, A.; Sonato, C.; Raimondi, C.; Gaudio, E.; Gazzaniga, P.; Gianni, W. Liquid biopsy in rare cancers: Lessons from hemangiopericytoma. Anal. Cell. Pathol. 2018, 2018, 9718585. [CrossRef]

30. Kuvendjiska, J.; Bronsert, P.; Martini, V.; Lang, S.; Pitman, M.B.; Hoeppner, J.; Kulemann, B. Non-metastatic esophageal adenocarcinoma: Circulating tumor cells in the course of multimodal tumor treatment. Cancers 2019, 11, E397. [CrossRef]

31. Curley, M.D.; Sabnis, G.J.; Wille, L.; Adiwijaya, B.S.; Garcia, G.; Moyo, V.; Kazi, A.A.; Brodie, A.; MacBeath, G. Seribantumab, an Anti-ERBB3 Antibody, Delays the Onset of Resistance and Restores Sensitivity to Letrozole in an Estrogen Receptor-Positive Breast Cancer Model. Mol. Cancer Ther. 2015, 14, 2642-2652. [PubMed]

32. Yonesaka, K.; Hirotani, K.; Kawakami, H.; Takeda, M.; Kaneda, H.; Sakai, K.; Okamoto, I.; Nishio, K.; Jänne, P.A.; Nakagawa, K. Anti-HER3 monoclonal antibody patritumab sensitizes refractory non-small cell lung cancer to the epidermal growth factor receptor inhibitor erlotinib. Oncogene 2016, 35, 878-886. [PubMed]

33. Kawakami, H.; Okamoto, I.; Yonesaka, K.; Okamoto, K.; Shibata, K.; Shinkai, Y.; Sakamoto, H.; Kitano, M.; Tamura, T.; Nishio, K.; et al. The anti-HER3 antibody patritumab abrogates cetuximab resistance mediated by heregulin in colorectal cancer cells. Oncotarget 2014, 5, 11847-11856. [CrossRef] [PubMed]

34. Yang, D.; Yang, J.; Li, S.; Jiang, M.; Cao, G.; Yang, L.; Zhang, X.; Zhou, Y.; Li, K.; Tang, S.T. Effects of RET, NRG1 and NRG3 Polymorphisms in a Chinese Population with Hirschsprung Disease. Sci. Rep. 2017, 7, 43222. [CrossRef] [PubMed]

35. Kimura, M.; Endo, H.; Inoue, T.; Nishino, K.; Uchida, J.; Kumagai, T.; Kukita, Y.; Kato, K.; Imamura, F.; Inoue, M. Analysis of ERBB ligand-induced resistance mechanism to crizotinib by primary culture of lung adenocarcinoma with EML4-ALK fusion gene. J. Thorac. Oncol. 2015, 10, 527-530. [PubMed]

36. Mota, J.M.; Collier, K.A.; Costa, R.L.B.; Taxter, T.; Kalyan, A.; Leite, C.A.; Chae, Y.K.; Giles, F.J.; Carneiro, B.A. A comprehensive review of heregulins, HER3, and HER4 as potential therapeutic targets in cancer. Oncotarget 2017, 8, 89284-89306. [PubMed]

37. Fedorenko, I.V.; Smalley, K.S. The complexity of microenvironment-mediated drug resistance. Genes Cancer 2015, 6, 367-368. [PubMed] 
38. Montero-Conde, C.; Ruiz-Llorente, S.; Dominguez, J.M.; Knauf, J.A.; Viale, A.; Sherman, E.J.; Ryder, M.; Ghossein, R.A.; Rosen, N.; Fagin, J.A. Relief of feedback inhibition of HER3 transcription by RAF and MEK inhibitors attenuates their antitumor effects in BRAF-mutant thyroid carcinomas. Cancer Discov. 2013, 3, 520-533. [PubMed]

39. Han, S.; Ren, Y.; He, W.; Liu, H.; Zhi, Z.; Zhu, X.; Yang, T.; Rong, Y.; Ma, B.; Purwin, T.J.; et al. ERK-mediated phosphorylation regulates SOX10 sumoylation and targets expression in mutant BRAF melanoma. Nat. Commun. 2018, 9, 28. [CrossRef] [PubMed]

40. Lewis, B.P.; Burge, C.B.; Bartel, D.P. Conserved seed pairing, often flanked by adenosines, indicates that thousands of human genes are microRNA targets. Cell 2005, 120, 15-20. [CrossRef] [PubMed]

41. Ebbing, E.A.; Medema, J.P.; Damhofer, H.; Meijer, S.L.; Krishnadath, K.K.; van Berge Henegouwen, M.I.; Bijlsma, M.F.; van Laarhoven, H.W.M. ADAM10-mediated release of heregulin confers resistance to trastuzumab by activating HER3. Oncotarget 2016, 7, 10243-10254. [PubMed]

42. Qiu, H.; Tang, X.; Ma, J.; Shaverdashvili, K.; Zhang, K.; Bedogni, B. Notch1 Autoactivation via Transcriptional Regulation of Furin, Which Sustains Notch1 Signaling by Processing Notch1-Activating Proteases ADAM10 and Membrane Type 1 Matrix Metalloproteinase. Mol. Cell. Biol. 2015, 35, 3622-3632. [PubMed]

43. Zhang, K.; Wong, P.; Salvaggio, C.; Salhi, A.; Osman, I.; Bedogni, B. Synchronized Targeting of Notch and ERBB Signaling Suppresses Melanoma Tumor Growth through Inhibition of Notch1 and ERBB3. J. Investig. Dermatol. 2016, 136, 464-472. [PubMed]

44. Qiu, H.; Zmina, P.M.; Huang, A.Y.; Askew, D.; Bedogni, B. Inhibiting Notch1 enhances immunotherapy efficacy in melanoma by preventing Notch1 dependent immune suppressive properties. Cancer Lett. 2018, 434, 144-151. [PubMed]

45. Costanzo, P.; Santini, A.; Fattore, L.; Novellino, E.; Ritieni, A. Toxicity of aflatoxin B1 towards the vitamin D receptor (VDR). Food Chem. Toxicol. 2015, 76, 77-79. [PubMed]

46. Roscilli, G.; Cappelletti, M.; De Vitis, C.; Ciliberto, G.; Di Napoli, A.; Ruco, L.; Mancini, R.; Aurisicchio, L. Circulating MMP11 and specific antibody immune response in breast and prostate cancer patients. J. Transl. Med. 2014, 12, 54. [CrossRef]

47. Fattore, L.; Ruggiero, C.F.; Pisanu, M.E.; Liguoro, D.; Cerri, A.; Costantini, S.; Capone, F.; Acunzo, M.; Romano, G.; Nigita, G.; et al. Reprogramming miRNAs global expression orchestrates development of drug resistance in BRAF mutated melanoma. Cell Death Differ. 2019, 26, 1267-1282.

48. Fattore, L.; Mancini, R.; Acunzo, M.; Romano, G.; Laganà, A.; Pisanu, M.E.; Malpicci, D.; Madonna, G.; Mallardo, D.; Capone, M.; et al. miR-579-3p controls melanoma progression and resistance to target therapy. Proc. Natl. Acad. Sci. USA 2016, 113, E5005-E5013.

49. Pisanu, M.E.; Maugeri-Saccà, M.; Fattore, L.; Bruschini, S.; De Vitis, C.; Tabbì, E.; Bellei, B.; Migliano, E.; Kovacs, D.; Camera, E.; et al. Inhibition of Stearoyl-CoA desaturase 1 reverts BRAF and MEK inhibitioninduced selection of cancer stem cells in BRAF-mutated melanoma. J. Exp. Clin. Cancer Res. 2018, 37, 318. [CrossRef]

50. Fattore, L.; Costantini, S.; Malpicci, D.; Ruggiero, C.F.; Ascierto, P.A.; Croce, C.M.; Mancini, R.; Ciliberto, G. MicroRNAs in melanoma development and resistance to target therapy. Oncotarget 2017, 8, 22262-22278.

51. Fattore, L.; Sacconi, A.; Mancini, R.; Ciliberto, G. MicroRNA-driven deregulation of cytokine expression helps development of drug resistance in metastatic melanoma. Cytokine Growth Factor Rev. 2017, 36, 39-48. [PubMed]

52. Fattore, L.; Mancini, R.; Ascierto, P.A.; Ciliberto, G. The potential of BRAF-associated non-coding RNA as a therapeutic target in melanoma. Expert Opin. Ther. Targets 2019, 23, 53-68. [PubMed]

(C) 2019 by the authors. Licensee MDPI, Basel, Switzerland. This article is an open access article distributed under the terms and conditions of the Creative Commons Attribution (CC BY) license (http://creativecommons.org/licenses/by/4.0/). 